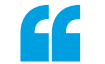

\section{Employing} lithium garnets as electrolytes substantially decreases the operating temperature by up to $200^{\circ} \mathrm{C}$

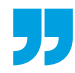

\title{
Sense and sustainability
}

The efficient detection and capturing of $\mathrm{CO}_{2}$ is an important strategy in slowing down global warming. Now, writing in Advanced Materials, Jennifer Rupp and colleagues report a simple, fast and stable potentiometric electrochemical lithium garnetbased $\mathrm{CO}_{2}$ sensor. This device can selectively detect a wide range of $\mathrm{CO}_{2}$ concentrations at substantially lower operating temperatures than state-of-the-art sensors.

In potentiometric gas sensors, the electrodes and the solid electrolyte determine analyte selectivity, stability, operating temperatures and measurable concentrations. Sodium-ion electrolytes are commonly used for the detection of $\mathrm{CO}_{2}$, but with operating temperatures above $400^{\circ} \mathrm{C}$, sensors based on these electrolytes require high power consumption.

Such sensors also lack longterm chemical stability in humid environments and can exhibit cross-reactivity with other gases. "A $\mathrm{CO}_{2}$ sensor should have fast reaction kinetics, be small in device form factor and operate at low temperatures to ensure efficient $\mathrm{CO}_{2}$ tracking in households and commercial areas," says Rupp.

To address these requirements, the researchers used lithium garnets, which are a commonly used electrolyte in solid-state batteries. $\mathrm{Li}_{7} \mathrm{La}_{3} \mathrm{Zr}_{2} \mathrm{O}_{12}$ has high ionic conductivity at room temperature, but lacks stability in contact with $\mathrm{CO}_{2}$ and $\mathrm{H}_{2} \mathrm{O}$ owing to the formation of $\mathrm{Li}_{2} \mathrm{CO}_{3}$. However, this reaction makes it an interesting candidate for detecting $\mathrm{CO}_{2}$.

Rupp and colleagues formed an electrochemical cell using tantalum-doped lithium garnets as electrolytes, gold as a reference electrode and gold- $\mathrm{Li}_{2} \mathrm{CO}_{3}$ as a working electrode. This device can operate at temperatures below

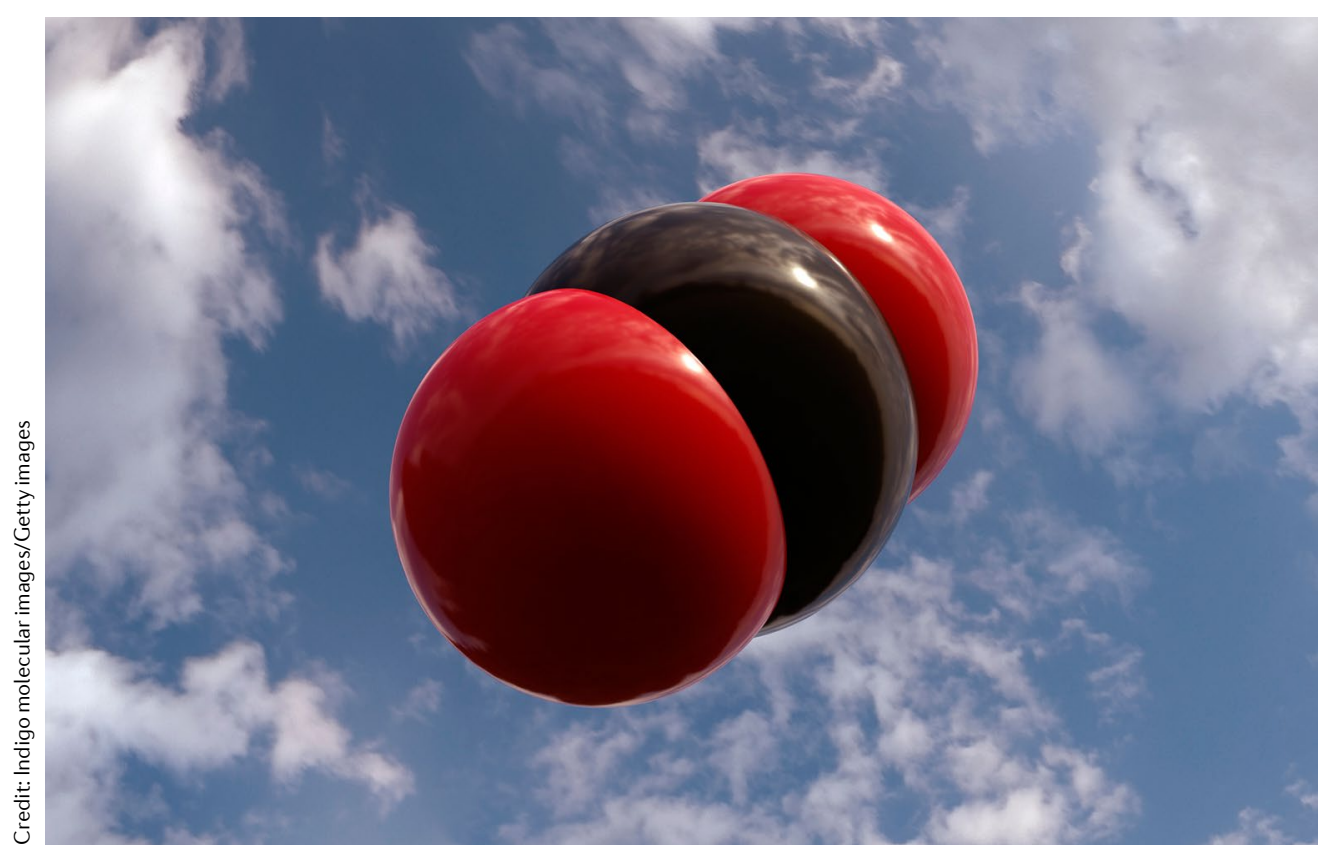

$400^{\circ} \mathrm{C}$, but remains stable up to $500^{\circ} \mathrm{C}$

Exposing the working and reference electrodes to the same gas environment revealed that the sensor is selective for $\mathrm{CO}_{2}$ and can detect $\mathrm{CO}_{2}$ concentrations between $0 \mathrm{ppm}$ and $4,000 \mathrm{ppm}$ in synthetic air.

The electromotive force (EMF) of the cell, which is the maximum potential difference between the two electrodes, responds to step changes in $\mathrm{CO}_{2}$ concentration between temperatures of $278^{\circ} \mathrm{C}$ and $366^{\circ} \mathrm{C}$. In this temperature range, the sensor is stable for a few days and EMF stabilization, that is, the response time, occurs within 60 seconds, which is substantially faster than the times achieved with sodium-ion based sensors at these temperatures.

"Employing lithium garnets as electrolytes substantially decreases the operating temperature by up to $200^{\circ} \mathrm{C}$, while maintaining the response time at less than 1 minute," explains Michal Struzik, first author of the paper.

In the future, Rupp and colleagues would like to tune the chemical composition and reaction kinetics of the electrodes to sense analytes other than $\mathrm{CO}_{2}$. Thinking more widely, the researchers envisage a new concept called lithionics, arising from the combination of solid-state lithium electrolyte conductors with sets of different electrodes. "The idea is to design a chip that can sense chemicals, compute data and store energy, based on one solid-state lithium conductor," comments Rupp.

Christine-Maria Horejs

ORIGINAL ARTICLE Struzik, M. et al. A simple and fast electrochemical $\mathrm{CO}_{2}$ sensor based on $\mathrm{Li}_{7} \mathrm{La}_{3} \mathrm{Zr}_{2} \mathrm{O}_{12}$ for environmental monitoring. $A d v$. Mater. https://doi.org/10.1002/adma.201804098 (2018) 